\title{
Simon on Problem-Solving Implications for New Organizational Forms
}

Foss, Kirsten; Foss, Nicolai Juul

Document Version

Final published version

Publication date:

2005

License

CC BY-NC-ND

Citation for published version (APA):

Foss, K., \& Foss, N. J. (2005). Simon on Problem-Solving: Implications for New Organizational Forms. Center for Strategic Management and Globalization. SMG Working Paper No. 8/2005

Link to publication in CBS Research Portal

\section{General rights}

Copyright and moral rights for the publications made accessible in the public portal are retained by the authors and/or other copyright owners and it is a condition of accessing publications that users recognise and abide by the legal requirements associated with these rights.

Take down policy

If you believe that this document breaches copyright please contact us (research.lib@cbs.dk) providing details, and we will remove access to the work immediately and investigate your claim. 


\title{
Simon on Problem-Solving: Implications for New Organizational Forms
}

\author{
Kirsten Foss \\ Nicolai J. Foss \\ SMG WP 8/2005
}

October 2005 
SMG Working Paper No. 8/2005

October 2005

ISBN: 87-91815-09-6

Center for Strategic Management and Globalization Copenhagen Business School

Porcelænshaven 24

2000 Frederiksberg

Denmark

www.cbs.dk/smg 


\title{
Simon on Problem-Solving: Implications for New Organizational Forms
}

\author{
Kirsten Foss \\ Copenhagen Business School \\ Center for Strategic Management and Globalization \\ Porcelainshaven 24; 2000 Frederiksberg; \\ Denmark; njf.smg@cbs.dk \\ Nicolai J. Foss \\ Copenhagen Business School \\ Center for Strategic Management and Globalization \\ Porcelainshaven 24; 2000 Frederiksberg; \\ Denmark; njf.smg@cbs.dk
}

26 May 2002; 21 May 2003; 6 January 2004; 7 October 2005

Keywords: Herbert Simon, problem-solving, new organizational forms.

JEL Code: D23, D83 


\title{
Simon on Problem-Solving: Implications for New Organizational Forms
}

\begin{abstract}
Two of Herbert Simon's best-known papers are "The Architecture of Complexity" and "The Structure of Ill-Structured Problems." We discuss the neglected links between these two papers, highlighting the role of decomposition in the context of problems on which constraints have been imposed as a general approach to problem solving. We apply these Simonian ideas to organizational issues, specifically new organizational forms. Specifically, Simonian ideas allow us to develop a morphology of new organizational forms and to point to some design problems that characterize these forms.
\end{abstract}




\section{Introduction}

Two of Herbert A. Simon's best known and most influential papers are the 1962 paper, “The Architecture of Complexity" and the 1973 paper on "The Structure of Ill-Structured Problems." Although the first paper is a contribution to general systems theory and the second one is a contribution to artificial intelligence, both may be seen as forming parts of an overall attempt to understand the structure of problems and problem-solving, the main themes in Simon's oeuvre (see also Newell and Simon 1972). However, while the 1962 paper has been widely cited by organizational scholars, notably by organizational economists (e.g., Williamson 1975; Loasby 1976; Egidi 1992; Nickerson and Zenger 2002; Langlois 2002), the 1973 paper has been been less noticed by organizational scholars (Mintzberg, Raisinghani and Thoret 1976; Grandori 2002 are exceptions). Simon himself was surely aware of the connections between his two contributions, but was not very explicit about them.

This paper discusses some of the connections between the two papers, as well as their implications for organizational theory, particularly the issue of new organizational forms. We bring out ideas in Simon's papers that have not been extensively applied in organization theory or applied at all, particularly the importance of imposing constraints on problems to make them manageable ("Problems and Problem Solving"). We then apply our discussion to organizational theory, specifically to new organizational forms in the context of internal organization (i.e., "internal hybrids"). We argue that an emphasis on problem solving allows for the identification of hitherto neglected benefits and limitations of such forms; thus, new insights in organizational design are put forward. Furthermore, a problem-solving approach also reveals the complicated morphology of the category of internal hybrids ("Application to New Organizational Forms"). 
In sum, the contribution of this paper is two-fold. First, it contributes to the Simon literature by discussing some neglected aspects of his work on problem solving. Second, it contributes in a novel manner to the literature on new organizational forms by applying Simonian ideas on problem-solving to design issues associated with these forms.

\section{Problems and Problem-Solving}

In this section, we very briefly review Simon $(1962,1973)$ and discuss and exemplify how the different dimensions of problems and the process of problem-solving that are identified in these two contributions relate to each other.

\section{"The Architecture of Complexity": Decomposability, Systems and Problems}

Simon introduces his paper as a contribution to systems theory, more specifically to the theory of complex systems, complexity being defined as obtaining when a large number of parts "interact in a nonsimple way" (1962: 468). Such complexity frequently takes the form of a hierarchy, that is, as a system that is composed of interrelated subsystems. Each one of these subsystems is, in turn, hierarchical in nature, until some elementary subsystem is reached at the lowest level. "In hierarchic systems," Simon explains, “... we can distinguish between the interactions among subsystems on the one hand, and the interactions within subsystems - i.e., among the parts of those subsystems - on the other" (1962: 473). This forms the basis for the famous distinction between decomposable systems, in which the interactions among the subsystems are negligible; non-decomposable systems, in which the interactions among the subsystems are essential; and nearly decomposable systems, in which the interactions among the subsystems are weak, but not negligible (1962: 129).

Simon then explains that an important aspect of what makes the social and natural world comprehensible is that they often involve phenomena that may be represented as nearly 
decomposable hierarchies; for example, "[s]ubparts belonging to different parts only interact in an aggregative fashion - the detail of their interaction can be ignored" (1962: 477). We can understand the system exactly because we can ignore these "details"; if we also had to comprehend the details it would be "beyond our capacities of memory and computation" (ibid.) to understand the full system.

In other words, the epistemological problem of comprehending a complex system is eased when the system is decomposable or nearly decomposable. The clear implication is that problem-solving may proceed by means of decomposing problems into sub-problems, ${ }^{1}$ and that there may be certain advantages to such an approach. Simon's famous story of the two watchmakers, Tempus and Hora, and their entirely different ways of making watches, one modular and one integral, exemplifies this idea, but strangely Simon does not explicitly state it in the 1962 paper (as we shall see, he is more explicit here in the 1973 paper). We further note some immediate implications:

- Problem-solving by means of decomposing problems into sub-problems is a manifestation of bounded rationality; an omniscient and perfectly calculating being would not need to decompose problems.

- Because of bounded rationality, a "... human being is more nearly a serial than a parallel information-processing system" (Simon 1962: 131). This means that in the problem-solving process, there are limits to the feasible simultaneous iteration between sub-problems.

- The preceding point further suggests that economizing with bounded rationality has a bearing on problem-solving. In itself, this implies that complex problems are not

\footnotetext{
1 This presupposes that the problem also has the features that characterize complex, hierarchical systems.
} 
likely to fully decomposed from the outset, because of the multitude of sub-problems (Camacho and Persky 1988).

- Bounded rationality makes time and attention scarce resources in problem-solving. Economizing with time and attention are key aspects of economizing with bounded rationality. There are many aspects of such economizing with bounded rationality, such as decomposing problems (as already mentioned), having people work in parallel on problems, and imposing constraints on problems. We treat the latter aspect in the following sections.

\section{"The Structure of Ill-Structured Problems"}

Simon's 1973 paper is a strong defence of artificial intelligence against the critique that certain problems are too ill-structured (or ill-defined) to be computationally solvable. Against this argument he submits that any ill-structured problem can be made structured through certain processes of transformation (hence the title), and that this renders them computable (solvable). In fact, Simon (1973: 186) forcefully argues that virtually all problems presented to problem solvers are, from the outset,

... best regarded as ill structured problems. They become well structured problems only in the process of being prepared for the problem solvers. It is not exaggerating much to say that there are no well structured problems, only illstructured problems that have been formalized for problem solvers.

Thus, well-structured problems are outcomes of problem-defining processes. Neglecting for the moment the nature of the processes, these outcomes may be characterized in terms of a number of requirements; thus, problems are well-structured when 
1) All initial elements that enter into the solution of the problem are known and described - for example, in chess the initial elements are the pieces, the board and rules of the game.

2) Trials on all level can be practically evaluated with respect to some effectiveness or efficiency criteria; also, the final proposed solution to the problem can be evaluated with respect to some such criterion.

3) The way in which the problem is solved must completely reflect the relevant laws that govern the external world — for example, the solution to a marketing problem must completely reflect how consumers react to changes in styles, prices, etc.

4) Solving the problem requires only practicable amounts of computation (i.e., at a cost substantially below infinite) and the relevant information which is needed to solve the problem can be gathered by means of practicable amounts of search (i.e., at search costs substantially below infinite). ${ }^{2}$

Evidently, these are very strict requirements, and few, if any, problems fully meet them. Even the playing of chess is not well-structured, since

[p]laying a game of chess — viewing this activity as solving a single problem involves continually redefining what the problem is. Even if we regard chess playing as a [well-structured problem] in the small (i.e., during the course of considering a single), by most criteria it must be regarded as an [ill-structured problem] in the large, i.e., over the course of the game (Simon 1973: 186).

\footnotetext{
2 We strongly stress that these criteria are our interpretation of the criteria listed in Simon (1973: 183). Simon's criteria are intended to apply to an artificial intelligence context, and do not apply without modification to problem-solving in organizations.
} 
Any problem that does not meet all of the above requirements is an ill-structured problem. The implication is that the distribution of problems between well-structured and entirely illstructured (i.e., none of the above requirements are met) is a continuum.

\section{Juxtaposing Dimensions of Problem-Solving: Some Examples}

Given that we may treat the degree of decomposability and the degree of structured'ness as different aspects of (complex, hierarchical) problems, we may also juxtapose the two dimensions in order to get a more detailed picture of the nature of problems; see Table $1 .{ }^{3}$

\section{XXXXXXXX Insert Table 1 Here XXXXXXXX}

The problem of making efficient use of dispersed knowledge in a competitive economy with private knowledge is an example of a problem that while decomposable - because each individual consumer and producers' allocation problem may be solved separately once prices are given - is also ill-structured. As Hayek (1945) explained, this is because of private knowledge which implies that most of the elements of the problem are not "given to a single mind" that can work out a solution.

Relaxing the strong assumptions underneath the standard economics portrayal of a competitive economy, notably that consumers and firms take prices as given, makes the allocation problem nearly decomposable. If firms have market power, strategic interaction arises. If contingent forward markets do not exist, investment plans have to be based on estimates of the size of complementary and competitive investments. Strategic decisions are more directly dependent upon the decisions made by close competitors, and investments decisions are directly dependent upon the investment decisions of direct competitors and

\footnotetext{
3 Note that in the table we talk about "nearly well-structured" problems rather than "well-structured," since according to Simon (1973) no problems are perfectly well-structured.
} 
suppliers, than of other firms in the economy. Hence, the economy-wide allocation problem becomes nearly decomposable (but is still ill-structured).

A possible candidate for a non-decomposable, ill-structured problem is building a violin with Stradivarius qualities (i.e., the timbre of a Stradivarius). The problem is ill-structured because there is an infinite set of kinds of wood, qualities of steel for strings, glue, etc. and the combination of these is an infinite set of combinations of these. It is non-decomposable because the timbre of the instrument depends on most of the elements that together constitute the violin.

As an example of a decomposable, nearly well-structured problem, a sub-problem in the design of automobile brakes described von Hippel and Tyre (1995: 10n) may arguably qualify: "The goal was that 'the brakes on car model A should not squeal when they are used under test conditions X.' To achieve this goal, it was permissible to manipulate only three well-understood variables, such as the composition of the brake lining material, in precisely specified ways." 4

An example of a nearly decomposable and nearly well-structured problem may be optimizing a simple production system, such as perhaps an assembly line, where certain workers with well-defined skills have to be matched with certain machines with welldefined functionalities, a sequence of tasks has to be determined, and the set of possible combinations is small.

Finally, non-decomposable, nearly well-structured problems may exist when there are complete technical complementarities between a small number of machines that each can be in a small number, and the problem is to select the optimal states.

\footnotetext{
4 Whether this is, in fact, an example of decomposability depends on whether there are interdependencies between the variables.
} 
While the above exemplifies various ways of classifying problems that are, as it were, given, it says nothing per se about problem-solving. We turn to this next, showing that when we consider the process of problem-solving, the two dimensions of problems are interdependent.

\section{Problem-Solving by Means of Decomposition and the Imposition of Constraints}

Decomposing problems. For many problems, it makes sense to treat the degree of decomposability and the degree of structured'ness as truly independent dimensions. For example, according to Hayek (1973), while the problem of allocating resources in a market economy may be treated as decomposable, it will — for fundamentally epistemological reasons - remain ill-structured, in the specific sense that no centralized mechanism will ever be able to gather and process all the relevant information that is necessary for computing a solution that is as efficient as the one that the market "computes" itself. The reason is that most economically relevant knowledge is inherently tacit and cannot be represented in a symbolic space so that it is given to computer manipulation. However, for some other problems, it appears that the two dimensions may not be so independent. For example, it is indeed conceivable that knowledge will emerge that will make the problem of building a Stradivarius more well-structured. Thus, more knowledge may be gained about the interaction among the many elements that together produce a Stradivarius, and about precisely which elements are important. This makes the problem decomposable. If, furthermore, the problem is also solvable with "practicable amounts of computation" (Simon 1973: 183), it is also (nearly) well-structured.

There more general implication is that the dimensions of decomposability and structured'ness are interdependent if we move from characterizing given problems in terms of the two dimensions to also consider the process of problem-solving. This is because one 
important way (not the only one) in which problem-solving often proceeds exactly is by means of decomposition. There are exceptions to this, of course. Notably, nondecomposable problems with few defining elements may be solved in a "holistic" manner.

However, even presumed non-decomposable problems may be given to decomposition. Thus, in the context of product development, Schaefer (1999) points out that some decomposition of product design problems may be beneficial even without any full understanding of the nature of interdependencies between sub-problems and therefore also of the nature of interdependencies in product design. He further argues that when a product design is characterized by dependencies between all design variables, an arbitrary decomposition of the design problem into elements is a way of increasing the understanding of the dependencies. If the product-development problem is initially partitioned in an arbitrary manner into sub-problems, the project development group can perform a sort of controlled experiment by solving some sub-problems, holding others constant, and trace the effects of the changes on the working of all other sub-problems. ${ }^{5}$ This allows for an ongoing process of iteration that ideally ends up with a coherent design. ${ }^{6}$

Such iteration between the problem-solving efforts of distributed, but highly interdependent, teams often characterizes major development efforts. Recent examples include the Boeing 777 development effort as well as Microsoft Windows (Cusumano 1997). For example, in the Boeing project, the team working on a 20 piece wing flap found 251 interferences where parts occupied the same coordinates in space, which gave rise to constant iteration between design efforts in different sub-problems (Sabbagh 1995). The necessity of iteration between subproblems and succeeding design changes follows from the impossibility of getting the

\footnotetext{
${ }^{5}$ Such a "preliminary modularization" of products is an effective way of reducing the time of experimentation needed to achieve an understanding of interdependencies between design variables (see Kirsten Foss 2001).
} 
decomposition right initially (cf. Simon 1973: 191). The following quotation from a software developer is illustrative:

A lot of time people don't realize that they are dependent on something. It's just not obvious. For example, you don't realize that you have a dependency because you are not familiar with that part of the code. Or a dependency just sort of materializes out of thin air because of a need and is tracked informally. Or instances where the solution to one dependency creates problems for a third party. The real problems with the hidden interdependencies - the ones that no one thought about pop up at the last minute" (quoted by Staudenmeyer and Cusumano 1998: 18-19).

The developer goes on to stress the need for carefully managing the process of iteration. ${ }^{7}$ Such management often mimics a controlled experiment in which all connected developments efforts, except for a few whose exact links need to be further investigated, are halted. This points more generally to the important role of imposing constraints for making problems solvable. We consider this in the following.

The role of constraints in problem-solving. Note in the examples in Table 1 that to the extent that problems have the property of being nearly well-structured, this is because constraints have been imposed on them. Consider the example of optimizing a simple production system. First, one aspect of making such a system "simple" is to define the system boundaries, that is, where the relevant interdependencies are most likely to be located. Second, optimizing the system is likely to require something like controlled experimentation,

\footnotetext{
${ }^{6}$ Not necessarily an optimal design in any absolute, global sense. We are dealing here with problems the solution landscapes of which are very rugged (in the sense defined, e.g., in Levinthal 1997).

7 Eppinger, Withney, Smith and Gebala (1994) find that iterations between product development tasks are reduced most when tasks are defined on the basis of a chart of the interaction between the design parameters specified by the designers.
} 
implying that the system is isolated from outside disturbances. Both impose closure on the problem, contributing to making it more well-structured. As many critics (one of the first being Loasby 1976) have pointed out, a general feature of optimization problems is that the constraints on the problem have already been defined through some usually non-analyzed process. This is sometimes entirely defensible. For example, under conditions resembling perfect competition the decision problems relating to pricing and supply are essentially defined for the decision makers because of the structural features of the situation. However, usually a crucial part of problem-solving is exactly the definition of those constraints that establishes some measure of closure around the problem.

In a sense, Simon's own work from the 1950s on satisficing search already takes such an approach (e.g., Simon 1955), because search becomes possible when aspiration levels are defined. However, it is arguably not until the 1973 paper that Simon explicitly introduces constraints as a crucial part of problem-solving. He gives several examples of problems (relating to shipbuilding and building a house) that are initially extremely ill-structured, but which through the imposition of constraints become well-structured. A key point in his discussion is that initial choices of constraints define the major interdependencies in the problem-solving effort, in the sense that these constraints define what are the (first levels of) subproblems and the relations between these.

Simon (1973: 189) seems to have been heavily influenced by Walter Reitman in his emphasis on constraints, whom he quotes on this matter (Reitman 1965: 169):

One of the interesting features of many of the problem instances ... is that even though they generally would be considered complex, they include very few constraints as given. Composing a fugue is a good example. Here the main initial constraint, and it is an open constraint at that, is that the end product be a fugue. 
All other constraints are in a sense supplementary, generated from one transformation of the problem to the next.

This is a profound insight with far-reaching implications. Thus, if through the process of problem-solving constraints are continuously generated, and one stage of the problemsolving effort sets the agenda for problem-solving in the next stage, this amounts to saying that problem-solving efforts are path-dependent and to some extent unpredictable. Another way of putting it is that learning follows an "adaptive walk" (Kauffman, Lobo and Macready 2000).

The setting of constraints also influences the other dimension of problem-solving, namely that of decomposing problems. In particular, initial constraints strongly influences the degree of decomposability sought. For example, developing a motorcycle that has to conform to certain requirements with respect to weight (namely that weight be low) and functionalities may mean that development efforts are not as decomposable as they would be if these requirements had been different (Ulrich and Eppinger 1995); modular developments are then dominated by integral ones.

The interaction between decomposing problems and setting constraints goes further than this. Thus, it may be a requirement in the design process that a given product design should be decomposable, as in modular design. Thus, decomposability becomes a constraint.

\section{Summing Up}

To sum, problem-solving is a process that involves both the setting of the constraints for the effort, and the decomposition of problems into sub-problems. Not all constraints can be defined initially, so that constraints arise endogenously in the process. This means that the fully decomposed problem cannot be laid out from the beginning. This further means that 
the process of problem-solving is path-dependent and partly unpredictable. An aspect of this is the capabilities of the problem-solver (experiences, knowledge, skills) play an important role for defining this path (in turn, these capabilities change in the process of problemsolving) (Dosi and Marengo 1994). We have further argued that the relation between the constraint and the decomposition of problems goes both ways. Thus, before decomposition can take place, closure needs to be established by means of defining constraints. In the following section, we apply the above notions to new organizational forms.

\section{Application to New Organizational Forms}

\section{Problem-Solving and Organization Design}

The idea that there is a connection between problem-solving and internal organization is not a new one. ${ }^{8}$ In fact, it may be said to be fundamental to the theory of organization design (e.g., Thompson 1967) in the sense that matching certain people with certain tasks in certain processes represents a recognition that certain constellations of the problem-solving capacity embodied in human capital produce certain organization-level problem-solving capabilities. Normatively, any given organization design should represent a particular decomposition of the overall problem of creating an organization that has a capacity for solving future, partly unanticipated problems, thus securing organizational survival. Ideally, the overall organization design — that is, the specification of what are the main interdependencies between tasks — should be undertaken by somebody who has an advantage in knowledge and judgment ("vision," in short) with respect to the overall architecture of the problems that

\footnotetext{
8 Indeed, many debates and insights in organizational theory (e.g., organic vs traditionally hierarchic organizations) as well as in strategic management (e.g., the strategy follows structure debate, the outsourcing debate) implicitly rely on the notion that organizational structure (a subset of internal organization) and problemsolving are somehow related. See Sah and Stiglitz (1985) for a particularly clear, if rather stylized, treatment of the issue.
} 
the organization will encounter. ${ }^{9}$ This is the same principle that Simon (1973: 191) applies in his discussion of an architect setting up what is in effect a problem-solving organization for the task of building a house. As he notes, part of the architect's "... professional training and subsequent learning is directed to organizing the process in such a way that the major interactions among components will be taken care of." Ideally, the organization "architect" should make his initial decomposition of the organizational design, and the imposition of constraints on this, in such a manner that the resulting allocation of power over decisions also reflect the structure of the problems that organization is designed to solve now and in the future.

The flip-side of the idea that there is a connection between problem-solving and internal organization is - as Brian Loasby (1976: 133) has perceptively noted — that an organizational structure “... not only determines where an organization's problems are worked on, but also helps to determine what problems they shall be, how they are defined, and what solutions will be attempted." Often organizations go wrong, and sometimes badly wrong, in their definition of what are the problems and how they should be solved. There are various reasons why this may happen. Notably, initial design errors may have been committed; thus, because of the complexity of the design task, "[i]nterrelations among the various well structured subproblems are likely to be neglected or underemphasized" (Simon 1973: 191). These neglected interrelations may turn out to have been essential in certain situations; for example, competitor firms who better understand interrelations between marketing and product development may surprise a negligent firm.

Also, as suggested above, the internal distribution of power may be important; thus, having a marketing-led (i.e., the marketing function can define some of the important constraints

\footnotetext{
9 The process of decomposing problems must necessarily involve an element of judgment; thus, in defining subproblems decision makers cannot have full knowledge of all the interdependencies
} 
for, e.g., production and product-development, cf. Carter 1995) firm in a technologically turbulent industry may be a recipe for failure. As this reasoning suggests, the decomposition of organizational design should reflect the structure of future problems; however, the relevant decomposition also partly determines the perception of, and reaction to, problems. We apply these notions to new organizational forms in the remainder of this section.

\section{New Organizational Forms}

Many writers have noted that firms, particularly those in knowledge-intensive industries, are increasingly experimenting with the ways in which they structure their boundaries (e.g., Helper, MacDuffie and Sabel 2000) and their internal organization (e.g., Miles et al. 1997; Child and McGrath 2001). They do so in order to increase their ability to absorb and build knowledge. Fundamental advances in IT and measurement technologies have facilitated these changes (Zenger and Hesterly 1997). These experiments with economic organization are often referred to by the of notions of "new organizational form" (Daft and Lewin 1993). New organizational forms may be classified as either external hybrids (Williamson 1996), that is, market exchanges infused with elements of hierarchical control, or internal hybrids (Zenger 2002), that is, hierarchical forms infused with elements of market control. We here concentrate on internal hybrids. Hybrid forms are characterized by relying upon crossfunctional processes, as well as extensive delayering and empowerment (Child and McGrath 2001: 137). The aim is to create highly specialized and motivated units by means of extensive delegation of discretion. Cross-functional processes substitute for hierarchy in the coordination of tasks.

\section{A Problem-Solving Perspective on Internal Hybrids}

We here apply the two dimensions of problem-solving, decomposition and structured'ness, to an understanding of the emergence, function, and morphology of internal hybrids. 
The emergence and function of internal hybrids. In a broad characterization, internal hybrids have emerged because firms confront new problems, the architecture of existing problems have changed, for example, because of changes in technology, and a number of elements in problem-solutions have changed. In this situation, internal hybrids may be adopted to impose structure on ill-defined problems, so that these problems become solvable and profitable solutions result. Like organizational design in general (Loasby 1976), internal hybrids represent specific ways in which the design of an organization reflects the definition and decomposition of a problem.

Firms confront new problems in the sense that the pace of technological development and innovation has increased, requiring increasing organizational flexibility. Moreover, internationalization and deregulation have changed the problem spaces that firms confront. The architecture of existing problems have changed, because, for example, advances in information and communication technology imply that interdependencies that were suppressed in earlier decompositions for reasons of economizing with communication costs may now be handled and exploited to the benefit of the firm.

For example, ICT imply that the "distance" between consumer and user preferences and production and product development can be made much smaller. The communication cost constraint imposed on this link in earlier decompositions of the problem may be significantly relaxed. This change is complementary to other changes in organization and production technology (Milgrom and Roberts 1990). If firms implement these complementary elements they may benefit, for example, in terms of lead time of product development.

Also, the emergence of novel ways of measuring (input and output) performance, such as activity-based costing, implies that it has become possible to measure organizational units in ways that go beyond traditional cost and profit-based measures, and to do so in a much 
more dis-aggregated manner (Zenger and Hesterly 1997). A crucial aspect of measurement systems such as activity-based costing is that they help to internalize externalities. Thus, interdependencies between organizational units, notably with respect to their use of common (i.e., corporate resources) that were difficult to identify and control with traditional measurement systems, may be handled in a more efficient manner with new measurement methods. Because these measurement methods allow for a better identification of the relevant interdependencies, they also allow for grouping tasks and activities in a manner that is different from the traditional criterion of how much they draw on common resources. Thus, with traditional measurement methods, a decomposition undertaken to reflect constraints imposed by available measurement methods may not be identical to the decomposition that reflects the architecture of the problem. This unavoidably results in significant externalities (what Thompson (1967) calls "residual interdependencies"), necessitating frequent intervention on the part of those who hold authority relative to the relevant interdependent units.

The advent of new methods of measuring performance (backed up by ICT innovations) implies that self-contained organizational units can be made much smaller. In turn, this further facilitates the measuring of performance, because the free-riding problem is much less severe in small groups than in large groups; more "high-powered" incentives can therefore be provided. From a problem-solving perspective, making self-contained organizational units smaller and more consistent with the overall architecture of the problem also implies that interdependencies that were hitherto suppressed become more visible. For example, the R\&D function may be decomposed into smaller units, each one of which is responsible for the design of a component of a modular products. 
To sum up on the function of internal hybrids, from a problem-solving perspective, they are implemented because they allow firms to obtain a better match between the decomposition of a problem and the corresponding decomposition of the organization. Implementing them has been facilitated by breakthroughs in ICT and measurement methods.

The morphology of internal hybrids. Like external hybrids, internal hybrids are quite diverse and exist in order to help the firm cope with problems of different types. Thus, some internal hybrids emerge to maximize the flexibility of the organization in turbulent environments (Miles et al. 1997), while others have the primary purpose of strengthening motivation (e.g., by means of empowerment and/or strengthened incentives) within firms in traditional industries (Zenger 2002). Some internal hybrids imply radical breaks with traditional hierarchies, while others take these as given, only adding a few novel coordination mechanisms. In terms of coordination mechanisms, internal hybrids represent different combinations of these (Grandori 2002). Therefore, internal hybrids may be characterized and distinguished along several dimensions. We here apply the two dimensions related to problem-solving that we have discussed so far; see Table 2.

\section{XXXXXXXX Insert Table 2 Here XXXXXXXX}

Internal hybrids are here categorized according to the types of problems that they are designed to handle; the table thus reflects an underlying notion of efficient alignment. We here discuss these problems and their dimensions, and the various organizational outcomes in terms of different kinds of internal hybrids produced by such a mapping.

Ill-structured problems arise, for example, in connection with technological breakthroughs, the opening up of new markets, changes in regulatory regimes, etc. Although firms per definition cannot exactly anticipate the architecture of such problems, they may nevertheless make provisions for handling the problems in terms of their organizational design; thus, " ... 
each part of [the] organization is a kind of experimental design" (Loasby 1976: 133). Managers will try to impose constraints on ill-structured problems. However, at least in the emerging stages of technologies, nobody may have a comparative advantage with respect to imposing constraints and making the initial decomposition in terms of organizational design. Paradoxically, a good response to such a situation may be to actually adopt a specific organizational design, namely a flat organization which through a bottom-up process turns out a number of suggestions about the character of the constraints that may impose more structure on the problem. In effect, a variety-creating evolutionary process is created by means of such a design. ${ }^{10}$ In turn, an "adhocracy" of this kind may give way to more structured forms as constraints become imposed on the problem,

To illustrate, consider the much cited case of the so-called "spaghetti organization" that was introduced in Danish hearing aids producer, Oticon in 1991, partly as a response to a threatening bankruptcy which was produced as a result of Oticon being unable to keep up with technological change in the hearing-aids industry (Morsing and Eiberg 1998; Foss 2003). Handling the situation was fundamentally an ill-structured problem: The basic constraint on future action was simply to turn out a number of profitable innovations in hearing-aids; how this should be accomplished was, however, fundamentally unclear. The spaghetti organization was adopted to handle this ill-structured problem. It was an extremely flat structure, encompassing only two hierarchical level, almost entirely project-based and characterized by substantial delegation of decision rights. For example, anybody could suggest, initiate and head a product development or marketing project, or sign up to any project. To a large extent, the organization was based on spontaneously forming projects, the idea being to emulate the spontaneous forces of market organization. Thus, the spaghetti

\footnotetext{
10 Indeed, some writers (e.g., Ravasi and Verona 2000) argue that a main benefit of new organizational forms is that they introduce "structural ambiguity," that is, unclear and/overlapping tasks and roles.
} 
organization qualifies as an internal hybrid (Foss 2003). However, as the spaghetti organization began to churn out (hugely) profitable innovations, increasing structure was imposed on the main strategic problems confronting the organization, for example, with respect to which technologies the organization should source and build. A more structured, less decomposed, organization with more hierarchical levels and less delegation, has later been adopted, reflecting a better definition of the overall set of problems confronting the organization. ${ }^{11}$ However, the present Oticon organization is still by all measures a rather decentralized organization, reflecting the need to keep options open in a situation where what may be happening in the hearing-aids industry is still rather unpredictable, so that the overall strategic problem remains ill-structured.

Internal hybrids may also be adopted in rather well-structured problem-situations. Their function is then not to embody experiments, but, for example, to increase lead time within well-understood technologies. Much of the recent work on modular products, technologies and organizations seems to take such an approach. Sanchez and Mahoney (1996: 64) argue that products influence the design of organizations, so that "...modularity in products becomes an important strategy for achieving modularity in organizational designs" (but see Foss 2001). Modular organizations, they explain, are characterized by loosely coupled design activities organized around loosely coupled self-managing teams; such organizations qualify as internal hybrids. Teams work within the information structure of a modular product architecture, in the sense that directions needed for coordination between the loosely coupled teams are provided by the standardized interface specification of product components. The notion of a standardized interface specification suggests that the relevant product or product development effort is well-understood. Thus, the relevant problem has

\footnotetext{
11 As Foss (2003) argues the spaghetti organization was also beset by certain fundamental incentive problems which also contributed to its demise.
} 
become rather well structured through the development of a product architecture and interface standards. When these architectures and standards are very well defined and expected to be long-lasting, the organization may be strongly decomposed (i.e., become "modular") (see also Langlois 2002).

Examples of internal hybrids that are adopted in well-structured problem-situations, but which does not necessarily imply that the organization becomes more decomposed may be the infusion of hierarchies of firms placed in traditional, stable industries with elements, such as some delegation of decision rights to lower levels in the hierarchy, possibly backed up with an increased use of performance pay.

Finally, it seems hard, perhaps impossible, to imagine examples of internal hybrids that are non-decomposable. This is because a major part of the design philosophy behind internal hybrids is to increase decomposition.

\section{Design Problems in Internal Hybrids}

The preceding section has argued that the set of internal hybrids is diverse, and that internal hybrids should be designed in a way that reflects the dimensions of the problems that they are supposed to solve. Design mistakes arise when the organizational form is misaligned to the underlying problem characteristics. Because many elements are involved in organizational design (i.e., the design and grouping of tasks, delegation of decision rights, information structures, and reward systems), such design mistakes take many different forms. Here we discuss some problems that become particularly conspicuous in a problemsolving perspective. We also briefly include some motivational issues that become particularly important in a problem-solving perspective. The organizational design problems that arise when problems are well structured are well covered in traditional organizational design theory (e.g., Thompson 1967; Galbraith 1974) and in organizational 
economics (e.g., Williamson 1975). We therefore concentrate on organizational design problems that arise when problems are ill structured.

Ill-structured problems represent basically uncertain situations, where imposing structure on the problem, that is, choosing some way of decomposing the problem and choosing constraints, are processes that typically demand considerable involvement and high bandwidth communication channels in order to set up an environment that can perform the dual tasks of creating variety and selecting among this variety. In this situation, a number of organizational design mistakes may be committed:

"Too much closure too fast": Management imposes constraints on the problem in order to make it well-structured; however, this constraining is done too fast. A number of upstart ecommerce firms had to learn the hard way that conceiving of e-business as primarily a fancy webpage was a too narrow closure to construct around the problem of creating a market and competiting in it. In particular, basic aspects of organizational design, notably the definition and allocation of tasks related to logistics, were neglected.

"Excessive decomposition": This problem is related to the above problem. It arises when management errorneously treats a problem as if it is well-structured, when in actuality it is ill-structured. This may be a result of imposing closure too fast. For example, management believes it knows the architecture of a problem, and designs the organization accordingly. Or, it perceives the tradeoff between the benefits and costs of flexible organization designs in such a way that flexibility is suppressed, for example in order to economize on communication costs. A special case of "excessive decomposition" is that a firm may become excessively decomposed relative to the environment. Thus, Chesbrough and Kusunoki (2001: 227) coin the notion of the "modularity trap" to refer to the problems that may arise when "[i]ntegral phases [of technology development] require much more centralized or 
integrated organizational structures that leverage managerial processes to coordinate poorly understood interdependencies inside the firm ... Firms that do not so align themselves are at risk of falling into ... a modularity trap, in which firms that achieved success by means of decentralized coordination via the market continue to rely on those methods for resolving integral technology issues" (2001: 227).

"Missing architectural knowledge." As Simon (1973: 191) a general problem of all schemes of decomposition is that there is a risk of not discovering some architectural knowledge, so that “[i]nterrelations among the various well-structured subproblems are likely to be neglected or underemphasized" (idem.). As Hoopes and Postrel (1999) argue, this may result in "glitches," that is, "... errors that occur because of a lack of interfunctional or interspecialty knowledge about problem constraints." For example, the problem of implementing ICT was in many organizations decomposed in such a manner that many of the potential (productivity) benefits of linking departments, functions, etc. with the use of ICT were neglected. In addition to not exploiting all possible opportunities from identifying interrelations among the subproblems is that "[s]olutions to particular subproblems are apt to be disturbed or undone at a later stage when new aspects are attended to" (idem.).

"Getting the incentives wrong": Internal hybrids amount to infusing hierarchies with elements of market control. A key aspect of market control is high-powered incentives, that is, reward schemes are strongly output-based. However, it is not entirely unproblematic to deploy such incentive schemes inside organizations. In particular, when problems are ill-structured and horizontal communication, extensive consultation between various hierarchical layers, and knowledge sharing may be crucial for generating the right closure around a problem, high-powered incentives may be dysfunctional. Instead of encouraging communication and knowledge-sharing, they may harm these beneficial practices, particularly to the extent that 
the incentives are based on individual performance and it is costly to measure and reward effort that is put into beneficial communication and knowledge-sharing.

\section{Conclusion}

In this paper we have discussed and juxtaposed key dimensions of problem-solving that are described in two key works by Herbert Simon $(1962,1973)$, and have drawn attention to the role of constraints in problem-solving. We have then demonstrated the usefulness of these dimensions to organizational theory by means of developing new insights for the understanding and design of new organizational forms, specifically internal hybrids. The present paper thus belongs to a small, but growing literature that builds on Simonian problem-solving premises in order to further organizational theory (Loasby 1976; Egidi 1992; Dosi and Marengo 1994; Grandori 2002; Nickerson and Zenger 2004). Although a problemsolving approach seems to be able to produce falsifiable conjectures (Table 2 is a first, primitive step in that direction), there is much to be done before serious empirical work can begin in this area. Notably, it is unclear how the dimensions of problems that we have discussed in the present paper may be operationalized and measured. The product development literature has a lead in this regard (Hippel 1990, 1994; Hippel and Tyre 1995; Staudenmeyer and Cusumano 1998), and some of the approaches in this literature may be leveraged in the context of organizational theory. Thus, we are confident that future work using a problem-solving approach in organizational theory will prove fruitful. 


\section{References}

Baldwin, Carliss and Kim Clark. 2000. Design Rules: The Power of Modularity. Cambridge, MA: MIT Press.

Camacho, Antonio and Joseph J. Persky. 1988. “The Internal Organization of Complex Teams: Bounded Rationality and the Logic of Hierarchies," Journal of Economic Behavior and Organization 9: 367-380.

Carter, Martin J. 1995. "Information and The Division of Labour: Implications for The Firms' Choice of Organization," The Economic Journal 105: 385-397.

Casson, Mark. 1994. “Why Are Firms Hierarchical?," Journal of the Economics of Business 1: 4776.

Chesbrough, Henry W. and Ken Kusunoki. 2001. “The Modularity Trap: Innovation, Technology Phase Shifts and the Resulting Limits of Virtual Organizations," in Ikujiro Nonaka and David J. Teece, eds. Managing Industrial Knowledge: Creation, Transfer, and Utilization. London: Sage.

Child, John and Rita McGrath. 2001. “Organizations Unfettered: Organizational Form in an Information Intensive Economy," Academy of Management Journal 44: 1135-1148.

Cusumano, Michael A. 1997. "How Microsoft Makes Large Teams Work Like Small Teams," Sloan Management Review: 9-20.

Daft, Richard L. and Lewin, Arie. 1993. "Where Are the Theories for the 'New' Organizational Forms? An Editorial Essay," Organization Science 4: i-iv.

Dosi, Giovanni and Luigi Marengo. 1994. "Some Elements of an Evolutionary Theory of Organizational Competences," in Richard W. Englander. Evolutionary Concepts in Contemporary Economics. Ann Arbor: University of Michigan Press.

Egidi, Massimo. 1992. "Organizational Learning, Problem Solving and the Division of Labour". In Simon, Herbert; Massimo, Egidi and Robin Maris (eds.), Economics, Bounded Rationality and the Cognitive Revolution, Aldershot: Edward Elgar.

Foss, Kirsten. 2001. “The Modularization of Products and Organizations: Improving Lead-Time in Product Development," downloadable from http://www.cbs.dk/link/papers

Foss, Nicolai. 2003. "Selective Intervention and Internal Hybrids: Interpreting and Learning from the Rise and Decline of the Oticon Spaghetti Organization," Organization Science 14: 331-349.

Galloway, Les. 1996. Operation Management: The Basics. London: International Thomson Business Press.

Grandori, Anna. 2002. “Cognitive Failures and Combinative Governance” Journal of Management and Governance 6: 252-260.

Hatchuel, Armand. 2001. "Towards Design Theory and Expandable Rationality," Journal of Management and Governance 5: 260-271.

Hayek, Friedrich A. von. 1945. "The Use of Knowledge in Society," in Friedrich A. von Hayek. 1948. Individualism and Economic Order. Chicago: University of Chicago Press. 
Hayek, Friedrich A. von. 1973. Law, Legislation and Liberty, vol 1: Rules and Order. Chicago: University of Chicago Press.

Helper, Susan, John Paul MacDuffie, and Charles Sabel. 2000. "Pragmatic Collaborations: Advancing Knowledge While Controlling Opportunism," Industrial and Corporate Change 9, 443-487.

Hippel, Eric von. 1990, “Task Partitioning: An Innovation Process Variable”. Research Policy 19: 407-418.

Hippel, Eric von. 1994. "'Sticky Information' and the Locus of Problem Solving: Implications for Innovation," Management Science 40: 429-439.

Hippel, Eric von and Marcie J. Tyre. 1995. "How Learning by Doing is Done: Problem Identification in Novel Process Equipment," Research Policy 24: 1-12.

Hoopes, David and Steven Postrel. 1999. "Shared Knowledge, 'Glitches,' and Product Development Performance," Strategic Management Journal 20: 837-865.

Jensen, Michael and William Meckling. 1992. "Specific and General Knowledge and Organizational Structure," in Lars Werin and Hans Wijkander, eds., Contract Economics. Oxford: Blackwell.

Kauffman, S., J. Lobo and W.G. Macready. 2000. “Optimal Search on a Technology Landscape," Journal of Economic Behavior and Organization 43: 141-166.

Langlois, Richard N. 2002. "A Modularity Theory of the Firm," in Nicolai J Foss and Peter G Klein, eds. 2002. Entrepreneurship and the Firm: Austrian Approaches to Economic Organization. Aldershot: Edward Elgar.

Levinthal, Daniel. 1997. “Adaptation on Rugged Landscapes," Management Science 43: 934950.

Loasby, Brian J. 1976. Choice, Complexity, and Ignorance. Cambridge: Cambridge University Press.

Miles, Raymond E., Charles C. Snow, John A. Mathews, Grant Miles and Henry J. Coleman, Jr. 1997. "Organizing in the Knowledge Age: Anticipating the Cellular Form," Academy of Management Executive 11: 7-20.

Mintzberg, Henry, Duru Raisinghani, and André Théorêt. 1976. "The Structure of 'Unstructured' Decision Processes,' Administrative Science Quarterly 21: 246-275.

Morsing, Mette and Kristian Eiberg, eds. 1998. Managing the Unmanageable For a Decade. Hellerup: Oticon.

Nickerson, Jackson and Todd Zenger. 2004. "A Knowledge-based Theory of the Firm: The Problem-Solving Perspective," Organization Science 15(6): 617-632

Ravasi, Davide and Gianmario Verona. 2000. “Organizing the Process of Knowledge Integration: The Benefits of Structural Ambiguity," forthcoming in Scandinavian Journal of Management.

Reitman, William. 1965. Cognition and Thought. New York.

Sabbagh, K. 1995. Twenty-First Century Jet: The Making of the Boeing 777. London: Macmillan.

Sah, Raaj and Joseph E. Stiglitz. 1985. "Human Fallibility and Economic Organization," American Economic Review 75 (Papers and Proceedings): 292-297. 
Sanchez, Ron and Joseph T. Mahoney. 1996. "Modularity, Flexibility, and Knowledge Management in Product and Organization Design". Strategic Management Journal 17: 63-76.

Schaefer, Scott. 1999. "Product Design Partitions with Complementary Components" Journal of Economic Behavior and Organization 38: 311-330.

Simon, Herbert A. 1955. "A Behavioral Theory of Rational Choice," Quarterly Journal of Economics 69: 99-118.

Simon, Herbert A. 1962. "The Architecture of Complexity," Proceedings of the American Philosophical Society 156: 467-482.

Simon, Herbert A. 1973. "The Structure of Ill-Structured Problems," Artificial Intelligence 4: 181-201.

Staudenmayer, Nancy and Michael A. Cusumano. 1998. "Alternative Designs for Product Component Integration," Working Paper, MIT.

Thompson, James D. 1967. Organizations in Action. New York: McGraw-Hill

Tirole, Jean. 1988. The Theory of Industrial Organization. Cambridge, MA: MIT Press.

Ulrich, Karl T. and Steven D. Eppinger. 1995. Product Design and Development, New Your: McGraw-Hill, Inc.

Wheelwright, Steven S. and Kim B. Clark. 1992. Revolutionizing Product Development, New York: The Free Press.

Williamson, Oliver E. 1975. Markets and Hierarchies. New York: Free Press.

Williamson, Oliver E. 1996. The Mechanisms of Governance. Oxford: Oxford University Press.

Zenger, Todd and William S. Hesterly. 1997. "The Disaggregation of Corporations: Selective Intervention, High-Powered Incentives, and Molecular Units," Organization Science 8: 209-222.

Zenger, Todd. 2002. "Crafting Internal Hybrids," International Journal of the Economics of Business. 
Table 1: Examples of Dimensionalized Problems

\begin{tabular}{|l|l|l|}
\hline & \multicolumn{1}{|c|}{ Ill-structured } & Nearly well-structured \\
\hline Decomposable & $\begin{array}{l}\text { The problem of making best } \\
\text { use of knowledge in a market } \\
\text { economy (Hayek). }\end{array}$ & $\begin{array}{l}\text { Optimizing a simple brake } \\
\text { system. }\end{array}$ \\
\hline Nearly decomposable & $\begin{array}{l}\text { The allocation problem in a } \\
\text { market economy with private } \\
\text { knowledge, but, e.g., } \\
\text { strategic behavior. }\end{array}$ & $\begin{array}{l}\text { Optimizing a simple } \\
\text { production system. }\end{array}$ \\
\hline Non-decomposable & $\begin{array}{l}\text { Building a violin with } \\
\text { Stradivarius qualities. }\end{array}$ & $\begin{array}{l}\text { Complete technical } \\
\text { complementarities between a } \\
\text { small number of machines. }\end{array}$ \\
\hline
\end{tabular}

Table 2: Internal Hybrids

\begin{tabular}{|l|l|l||}
\hline \multicolumn{1}{|c|}{} & \multicolumn{1}{|c|}{$\begin{array}{c}\text { Ill-structured (loose } \\
\text { constraints imposed on } \\
\text { problems) }\end{array}$} & $\begin{array}{c}\text { Nearly well-structured } \\
\text { (tight constraints imposed } \\
\text { on problems) }\end{array}$ \\
\hline Decomposed & $\begin{array}{l}\text { Flat adhocracies. } \\
\text { The Oticon spaghetti } \\
\text { organization. }\end{array}$ & $\begin{array}{l}\text { Modular organizations } \\
\text { (Sanchez and Mahoney } \\
1996) .\end{array}$ \\
\hline Nearly decomposed & $\begin{array}{l}\text { The present Oticon } \\
\text { organization. }\end{array}$ & $\begin{array}{l}\text { Use of performance pay and } \\
\text { certain empowerment } \\
\text { practices in a traditional, } \\
\text { functional organization. }\end{array}$ \\
\hline Non-decomposed & Non-existent & Non-existent \\
\hline
\end{tabular}




\section{SMG - Working Papers \\ www.cbs.dk/smg \\ 2003}

2003-1: Nicolai J. Foss, Kenneth Husted, Snejina Michailova, and Torben Pedersen: Governing Knowledge Processes: Theoretical Foundations and Research Opportunities.

2003-2: Yves Doz, Nicolai J. Foss, Stefanie Lenway, Marjorie Lyles, Silvia Massini, Thomas P. Murtha and Torben Pedersen: Future Frontiers in International Management Research: Innovation, Knowledge Creation, and Change in Multinational Companies.

2003-3: Snejina Michailova and Kate Hutchings: The Impact of In-Groups and OutGroups on Knowledge Sharing in Russia and China CKG Working Paper.

2003-4: Nicolai J. Foss and Torben Pedersen : The MNC as a Knowledge Structure: The Roles of Knowledge Sources and Organizational Instruments in MNC Knowledge Management CKG Working Paper.

2003-5: Kirsten Foss, Nicolai J. Foss and Xosé H. Vázquez-Vicente: “Tying the Manager's Hands": How Firms Can Make Credible Commitments That Make Opportunistic Managerial Intervention Less Likely CKG Working Paper.

2003-6: Marjorie Lyles, Torben Pedersen and Bent Petersen: Knowledge Gaps: The Case of Knowledge about Foreign Entry.

2003-7: Kirsten Foss and Nicolai J. Foss: The Limits to Designed Orders: Authority under "Distributed Knowledge" CKG Working Paper.

2003-8: Jens Gammelgaard and Torben Pedersen: Internal versus External Knowledge Sourcing of Subsidiaries - An Organizational Trade-Off.

2003-9: Kate Hutchings and Snejina Michailova: Facilitating Knowledge Sharing in Russian and Chinese Subsidiaries: The Importance of Groups and Personal Networks Accepted for publication in Journal of Knowledge Management.

2003-10: Volker Mahnke, Torben Pedersen and Markus Verzin: The impact of knowledge management on MNC subsidiary performance: the role of absorptive capacity CKG Working Paper.

2003-11: Tomas Hellström and Kenneth Husted: Mapping Knowledge and Intellectual Capital in Academic Environments: A Focus Group Study Accepted for publication in Journal of Intellectual Capital CKG Working Paper.

2003-12: Nicolai J Foss: Cognition and Motivation in the Theory of the Firm: Interaction or "Never the Twain Shall Meet"? Accepted for publication in Journal des Economistes et des Etudes Humaines CKG Working Paper.

2003-13: Dana Minbaeva and Snejina Michailova: Knowledge transfer and expatriation practices in MNCs: The role of disseminative capacity.

2003-14: Christian Vintergaard and Kenneth Husted: Enhancing selective capacity through venture bases. 


\section{4}

2004-1: Nicolai J. Foss: Knowledge and Organization in the Theory of the Multinational Corporation: Some Foundational Issues

2004-2: Dana B. Minbaeva: HRM practices and MNC knowledge transfer

2004-3: Bo Bernhard Nielsen and Snejina Michailova: Toward a phase-model of global knowledge management systems in multinational corporations

2004-4: Kirsten Foss \& Nicolai J Foss: The Next Step in the Evolution of the RBV: Integration with Transaction Cost Economics

2004-5: Teppo Felin \& Nicolai J. Foss: Methodological Individualism and the Organizational Capabilities Approach

2004-6: Jens Gammelgaard, Kenneth Husted, Snejina Michailova: Knowledge-sharing Behavior and Post-acquisition Integration Failure

2004-7: Jens Gammelgaard: Multinational Exploration of Acquired R\&D Activities

2004-8: Christoph Dörrenbächer \& Jens Gammelgaard: Subsidiary Upgrading? Strategic Inertia in the Development of German-owned Subsidiaries in Hungary

2004-9: Kirsten Foss \& Nicolai J. Foss: Resources and Transaction Costs: How the Economics of Property Rights Furthers the Resource-based View

2004-10: Jens Gammelgaard \& Thomas Ritter: The Knowledge Retrieval Matrix: Codification and Personification as Separate Strategies

2004-11: Nicolai J. Foss \& Peter G. Klein: Entrepreneurship and the Economic Theory of the Firm: Any Gains from Trade?

2004-12: Akshey Gupta \& Snejina Michailova: Knowledge Sharing in Knowledge-Intensive Firms: Opportunities and Limitations of Knowledge Codification

2004-13: Snejina Michailova \& Kate Hutchings: Knowledge Sharing and National Culture: A Comparison Between China and Russia

\section{5}

2005-1: Keld Laursen \& Ammon Salter: My Precious - The Role of Appropriability Strategies in Shaping Innovative Performance

2005-2: Nicolai J. Foss \& Peter G. Klein: The Theory of the Firm and Its Critics: A Stocktaking and Assessment

2005-3: Lars Bo Jeppesen \& Lars Frederiksen: Why Firm-Established User Communities Work for Innovation: The Personal Attributes of Innovative Users in the Case of Computer-Controlled Music

2005-4: Dana B. Minbaeva: Negative Impact of Hrm Complementarity on Knowledge Transfer in Mncs

2005-5: Kirsten Foss, Nicolai J. Foss, Peter G. Klein \& Sandra K. Klein: Austrian Capital Theory and the Link Between Entrepreneurship and the Theory of the Firm 
2005-1: Nicolai J. Foss: The Knowledge Governance Approach

2005-2: Torben J. Andersen: Capital Structure, Environmental Dynamism, Innovation Strategy, and Strategic Risk Management

2005-3: Torben J. Andersen: A Strategic Risk Management Framework for Multinational Enterprise

2005-4: Peter Holdt Christensen: Facilitating Knowledge Sharing: A Conceptual Framework

2005-5 Kirsten Foss \& Nicolai J. Foss: Hands Off! How Organizational Design Can Make Delegation Credible

2005-6 Marjorie A. Lyles, Torben Pedersen \& Bent Petersen: Closing the Knowledge Gap in Foreign Markets - A Learning Perspective

2005-7 Christian Geisler Asmussen, Torben Pedersen \& Bent Petersen: How do we capture "Global Specialization" when measuring firms' degree of internationalization?

2005-8 Kirsten Foss \& Nicolai J. Foss: Simon on Problem-Solving: Implications for New Organizational Forms 